\title{
Operational Efficiency Evaluation of Iron Ore Logistics at the Ports of Bohai Bay in China: Based on the PCA-DEA Model
}

\author{
Jihong Chen,, ${ }^{1,2}$ Zheng Wan,,3 Fangwei Zhang,, Nam-kyu Park, \\ Xinhua He, ${ }^{1}$ and Weiyong Yin ${ }^{1}$ \\ ${ }^{1}$ College of Transport and Communications, Shanghai Maritime University, Shanghai 201306, China \\ ${ }^{2}$ Shanghai International Shipping Institute, Shanghai 200082, China \\ ${ }^{3}$ Institute of Transportation Studies, University of California Davis, Davis, CA 95616, USA \\ ${ }^{4}$ School of Port Logistics, Tong Myong University, Busan 608711, Republic of Korea \\ Correspondence should be addressed to Zheng Wan; mrwan@ucdavis.edu
}

Received 19 July 2015; Revised 26 November 2015; Accepted 3 December 2015

Academic Editor: Sergio Preidikman

Copyright (c) 2016 Jihong Chen et al. This is an open access article distributed under the Creative Commons Attribution License, which permits unrestricted use, distribution, and reproduction in any medium, provided the original work is properly cited.

\begin{abstract}
Operational efficiency is significant for the comprehensive competitiveness of a port. In this study, we use a principal component analysis-data envelopment analysis (PCA-DEA) integrated model to evaluate the operational efficiency of iron ore logistics at the ports of Bohai Bay, China. The key indicators and systematic framework are established for logistics efficiency research. We consider the PCA-DEA integrated model as a practical tool for evaluating and analyzing the relative efficiency of the iron ore logistics of each port in that area. The proposed method consists of a two-stage research and analysis that begins with PCA. In the first stage, we use PCA to obtain 6 synthetic indicators, including 4 input indicators and 2 output indicators, from 15 original indicators. In the second stage, the standard DEA approach is used with the specific synthetic indicators. The evaluation results of the selected ports from the integrated PCA-DEA model are compared and discussed. The comparison of the evaluation results indicates that the PCA-DEA model provides a practical and powerful tool for the investigation of the port logistics problem. With this integrated model, a comparison analysis and further research into the iron ore logistics efficiency of different ports in the area are presented. Finally, discussions and suggestions are provided.
\end{abstract}

\section{Introduction}

China's rapid urbanization process has empowered its infrastructure construction and triggered the need for strategic materials, such as iron ore and steel. In recent years, the exported quantity and port throughput of iron ores in China have constantly increased. Iron ore logistics in coastal ports has become an important part of port development. The ports of Bohai Bay serve as the pivotal base for the transport and handling of iron ore in China. The annual throughput of iron ore accounts for over $60 \%$ of the total throughput of China. As the contradiction of demand and supply of iron ore and the cost awareness of enterprises on logistics intensify, iron ore has become an increasingly important commodity at the ports of Bohai Bay, China. The competition in iron ore transport and logistics services among the ports of Bohai Bay is escalating. The evaluation of iron ore logistics in each port and the increase in logistics efficiency are the major pathways to improve the iron ore logistics service and to enhance the competitiveness of the ports.

Port efficiency evaluation aims to promote the development of ports and enhance their performance competitiveness. As for the iron ore port logistics management, efficiency evaluation is not only a powerful tool for port authorities to improve port management performance but also a useful approach for the government to gain very important information on iron ore port planning and development. The purpose of this paper is to introduce an extension to operational efficiency evaluation problem in port industry, namely, operational efficiency evaluation of iron ore logistics of ports, to propose an integrated mathematical model of principal component analysis (PCA) and data envelopment 
analysis (DEA) for this kind of evaluation research work and to evaluate the model by the means of an empirical study of the main ports of Bohai Bay in China.

The rest of this paper is structured as follows. Section 2 contains a description of relevant, existing literature. In Section 3, evaluation indicators and evaluation model are described. Specific empirical study on the evaluation of the operational efficiency of the iron ore logistics in Bohai Bay in China is carried out in Section 4. Section 5 concludes.

\section{Literature Review}

The study on port efficiency can be dated back to the 1980s with the use of one or several indicators. With regard to the development performance of ports and relevant regions, many studies have been conducted using different methods and perspectives. The methods for evaluating the development performance of ports and relevant regions are divided into nonparametric or parametric. The representative nonparametric method is the data envelopment analysis (DEA). Depending on their needs, scholars can select various input and output indicators from different aspects. The model for the evaluation of port operational efficiency is constructed, and different ports are used for the evaluation. Roll and Hayuth used DEA approach as a tool to evaluate port performance and the model was demonstrated by a hypothetical numerical example where the performances of 20 ports are compared [1]. Different ports and their efficiencies have been compared and Tongzon selected some typical Australian and other international ports for efficiency measurement using data envelopment analysis [2]. In order to incorporate different port efficiency measures, some scholars used principal component analysis (PCA) [3]. Tongzon and Heng applied a stochastic frontier model to investigate the quantitative relationship between port ownership structure and port efficiency [4]. Wu and Lin conducted revealed comparative advantage (RCA) analysis to investigate India's logistics competitiveness and used data envelopment analysis (DEA) to analyze the efficiency of India's container port operations [5]. To improve the application of DEA model in efficiency evaluation, some scholars made special emphasis on the input and output factors selected in the DEA models employed in different fields or port areas [6, 7]. Cullinane et al. introduced the time factor into the port efficiency evaluation model. Using panel data, the main container ports in the world were selected as samples to analyze relative efficiency [8]. Chen et al. investigated the spatial distribution characteristics and formation mechanism of the port service industry in Guangzhou. The location factor of logistics efficiency in the port service industry was discussed [9]. Wang and Ducruet synthesized the theoretical models of Hayuth and Notterboom to study the evolutionary mechanism of a container port system and the different phases of port logistics development [10]. Liang et al. used the data of port logistics enterprises in Shanghai. Methods such as geographic information system spatial analysis and mathematical statistics were utilized to observe the spatial pattern and evolution of port logistics enterprises and to identify the key influence factors [11]. Lan et al. used the DEA-Malmquist total factor productivity index to evaluate the dynamic efficiency of the main coastal ports in Chinese mainland, Taiwan, Hong Kong, and Macao. The competitive status and potentials of different harbors were compared [12]. Using the DEA method, Sun and Xiao compared the relative economic operational efficiency of ports in the 11 coastal provinces of China for one specific year and proposed suggestions for the sustainable development of the port economy [13]. Tan et al. used the port logistics efficiency indicator system for the analysis of port logistics efficiency in Liaoning Province during 2001-2009. By establishing the indicator system for the coordinated development between port logistics and hinterland economy, they calculated the coordination degree between port logistics and hinterland economy in 2002-2009, with 2001 as the base year [14]. Li et al. introduced the DEA-based binary relative evaluation model into the measurement of port logistics efficiency. Taking the production efficiency and $X$-efficiency as basis, they proposed the model for estimating comprehensive port logistics efficiency [15]. Lee et al. used slacks-based data envelopment analysis model to assess the environmental efficiency of port cities [16]. Yuen et al. investigated how the involvement of foreign and local ownerships, intra- and interport competition, and hinterland affects the container terminal efficiency in China and its neighboring countries [17]. Pjevčević et al. applied DEA method in measuring and analyzing the efficiencies of ports on the river Danube. DEA window analysis was used to determine the efficiency of ports and to observe the possibility of changes in the port efficiency over time [18].

The parametric method for port efficiency evaluation is mainly stochastic frontier analysis (SFA), which calculates the deviation degree of sample ports from the port of efficiency frontier to estimate port efficiency. In fact, the port of efficiency frontier does not actually exist but is called so because it is the optimal efficiency used to compare other ports. The port of efficiency frontier varies with different sets of port samples. Aigner et al. proposed an SFA for performance measurement, which lays the theoretical foundation for further development. The stochastic frontier method can be conveniently applied in many fields [19]. Relevant scholars have used this method for port efficiency evaluation [2025]. As a typical parametric method, the SFA considers the errors caused by statistics and observations. However, the presumed frontier function has certain subjectivity [26]. The evaluation indicators are uncertain in either the parametric or the nonparametric method for port performance evaluation. An inconsistency among statistical evaluation indicators of different ports may also be observed [24]. In recent years, several multiattribute decision-making methods have been adopted for port efficiency or performance evaluation; these methods include fuzzy analytical hierarchy process, quality function deployment, and fuzzy analytic network process [27-31]. Although these methods are flexible and easy to use, the appropriate evaluation indicators are difficult to design, and the interference between indicators may be considerable.

As a nonparametric method, the DEA has been extensively applied in port efficiency evaluation despite its defects. 
Thus, the evaluation method for real applications should be selected depending on the conditions and sample data [32]. The DEA method cannot compare the units of technology efficiency. Considering the effect of stochastic factors on the system, the technology efficiency of the DEA method can be significantly affected when an anomaly exists in the samples. The defects of the DEA method have been addressed through a number of improvements that fit the specific applications or through the combination of other methods. Simões and Marques evaluated the performance of a set of European seaports by means of robust nonparametric approaches using order-m and bootstrap procedures [30]. Carvalho et al. presented the major features of Iberian seaports, analyze their governance model, and evaluate their inefficiency based on the nonparametric frontier technique of data envelopment analysis (DEA) and on a bootstrap resampling method [33]. In some cases, a completely different method is used to replace the DEA method. Al-Eraqi et al. used the DEA decomposition of the Malmquist index as an improvement of the DEA model to evaluate port efficiency [34]. Lee et al. established an improved RDEA method to rank a range of container ports by efficiency. This ranking was used as basis in the identification of countermeasures for enhancing port efficiency [35]. Wan et al. implemented a two-stage approach of DEA and Tobit regression. First, the container port efficiency was measured by data envelopment analysis (DEA). Then, Tobit regression analysis was undertaken to explore the relationship between DEA scores and ground transportation conditions [36]. Jiang et al. introduced the strongly efficient frontier (SEF) and strongly inefficient frontier (SIF) and then proposed several models to calculate various distances between DMUs and both frontiers [37].

DEA was a very useful method to evaluate port and logistics efficiency. However, due to the mutual interference of the evaluation index, the application of DEA method is limited. Therefore, scholars have actively improved the DEA method, eliminating the mutual interference of the evaluation index. With a focus on the defects of the DEA method, scholars usually use the principal component analysis (PCA) in combination with the DEA method for efficiency evaluation. In this manner, the interference between indicators is expected to be removed $[38,39]$. In the present study, we adopt the integrated PCA-DEA model to evaluate the operational efficiency of iron ore logistics at the ports of Bohai Bay. The integrated model fully utilizes the advantage of PCA in extracting characteristic indicators. By overcoming mutual interferences between the indicators and transforming multiple indicators into a few synthetic indicators, the integrated model fulfills the function of the DEA model in the evaluation of the relative efficiency of the decision-making unit (DMU).

\section{Evaluation Indicators and Evaluation Model}

3.1. Evaluation Indicator System. A port logistics system has a complex intrinsic structure. The evaluation indicators constitute a system with intrinsic connections. Many factors influence the operational efficiency of the iron ore logistics of ports. Typical factors include the natural conditions of the port, infrastructures related to iron ore logistics, scale and capacity of the iron ore logistics service, and iron ore collection and distribution system.

The natural conditions of a port are the preconditions for the iron ore logistics operation of the port. Serving as the basic operation conditions for the iron ore logistics system, the natural conditions ensure that ships can enter and depart conveniently. The major indicators in this aspect are the water depth of the navigation channel, width of the main navigation channel, and water depth at the berth. The infrastructures related to iron ore logistics service reflect the hardware and service capacities of a port in iron ore logistics operation. Infrastructures related to iron ore logistics service are directly related to the actual production capacity and development potential of the iron ore logistics of the port. The indicators in this aspect include the total length of the berth, number of berths, area of the iron ore storage yard, and number of iron ore loading machines. The scale and capacity of iron ore logistics service are the core of iron ore logistics activities and performance. This factor can be used to evaluate the effect of the iron ore logistics business of a port. The capacity and efficiency of the iron ore logistics of a port are largely determined by this aspect. The relevant indicators include iron ore carrying capacity, iron ore throughput, and growth of iron ore throughput. The iron ore collection and distribution capacity of a port reflects the ability of the port to coordinate loading and unloading operations, centralization, and commodity distribution. The capacity in this field directly influences the iron ore logistics efficiency of the port. The relevant indicators include the length of the railway line in the port, ship-loading efficiency of a single iron ore line, and iron ore unloading efficiency.

The aforementioned influence factors and relevant indicators are summarized. The factors that have an impact on the iron ore ports of China and iron ore logistics efficiency are considered. The input and output attributes of the indicators are taken into account to determine the evaluation system for the indicators of the operational efficiency of the iron ore logistics at the ports of Bohai Bay, China (see Table 1). The original data of the influence factors and relevant indicators can be got from China Port Yearbook and China Statistical Yearbook.

3.2. Evaluation Method. PCA is aimed at reducing dimensionality and transforming multiple indicators into few synthetic indicators. This method can eliminate the correlations among the indicator samples. The representative indicators are extracted under the premise of preserving the key information of the samples. In the analytic process, the weights of the major indicators are calculated, and the principal components are taken as the values of the synthetic indicators of the DMU [38]. If only the DEA method is adopted in the iron ore logistics efficiency evaluation of the ports, then the design of the evaluation indicators will significantly affect the evaluation results. The iron ore logistics efficiency evaluation involves several indicators, and weighing between the number and independence of the indicators is difficult. 
TABLE 1: Evaluation system for the indicators of the operational efficiency of the iron ore logistics at the ports of Bohai Bay, China.

\begin{tabular}{|c|c|c|}
\hline Primary indicator & Secondary indicator & $\begin{array}{c}\text { Properties and symbols } \\
\text { of the indicators }\end{array}$ \\
\hline \multirow{3}{*}{$\begin{array}{l}\text { Natural conditions of the } \\
\text { ports }\end{array}$} & Water depth of the navigation channel & Input indicator $X_{1}$ \\
\hline & Width of the main navigation channel & Input indicator $X_{2}$ \\
\hline & Average water depth of the berth & Input indicator $X_{3}$ \\
\hline \multirow{6}{*}{$\begin{array}{l}\text { Infrastructures related to } \\
\text { iron ore logistics service }\end{array}$} & Total length of the berth & Input indicator $X_{4}$ \\
\hline & Number of berths & Input indicator $X_{5}$ \\
\hline & Number of berths of over 150,000 tons & Input indicator $X_{6}$ \\
\hline & Area of the iron ore storage yard & Input indicator $X_{8}$ \\
\hline & Volume of the iron ore stock & Input indicator $X_{9}$ \\
\hline & Number of loading and unloading machines & Input indicator $X_{11}$ \\
\hline \multirow{3}{*}{$\begin{array}{l}\text { Scale and capacity of the } \\
\text { iron ore logistics services of } \\
\text { the port }\end{array}$} & Designed iron ore carrying capacity & Input indicator $X_{7}$ \\
\hline & Iron ore throughput & Output indicator $Y_{1}$ \\
\hline & Growth of iron ore throughput & Output indicator $Y_{2}$ \\
\hline \multirow{3}{*}{$\begin{array}{l}\text { Iron ore collection and } \\
\text { distribution capacity }\end{array}$} & Length of the railway line in the port & Input indicator $X_{10}$ \\
\hline & Ship-loading efficiency of a single iron ore line & Output indicator $Y_{3}$ \\
\hline & Iron ore unloading efficiency & Output indicator $Y_{4}$ \\
\hline
\end{tabular}

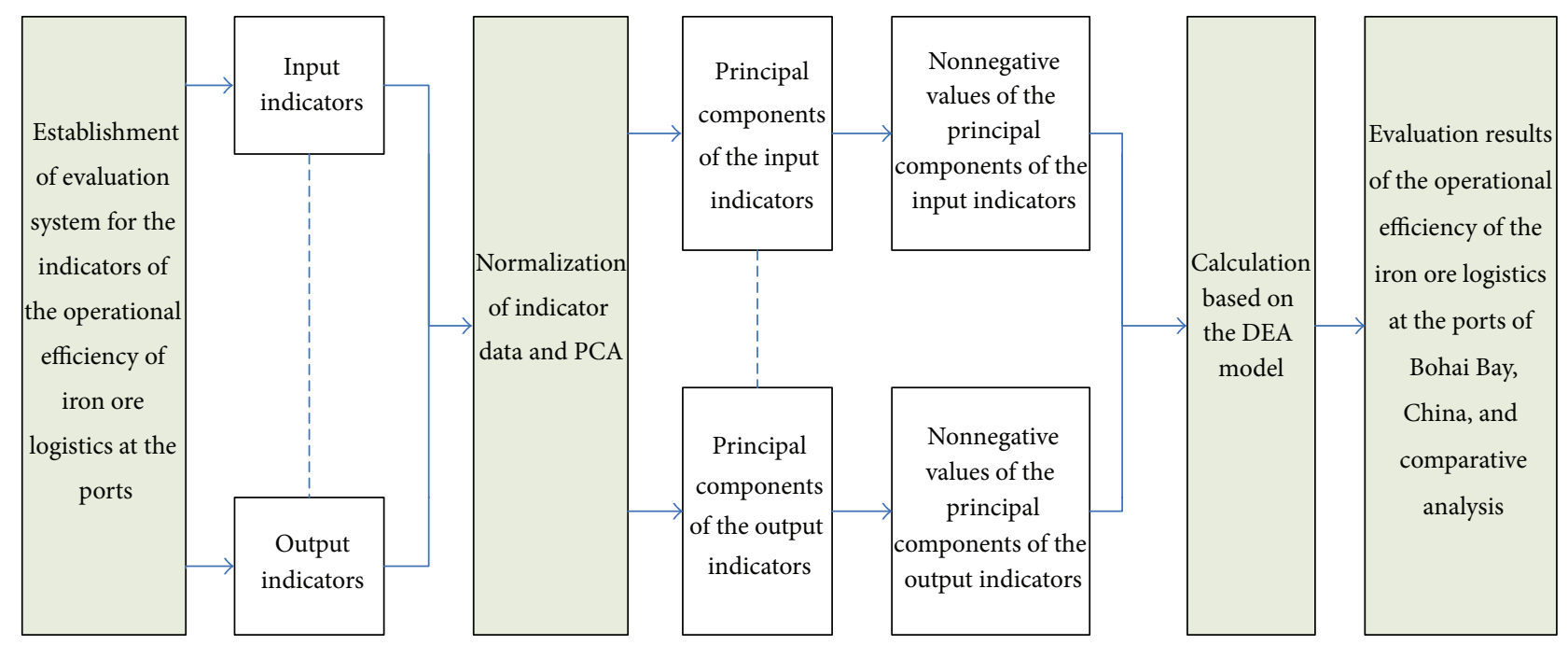

FIgUrE 1: Procedures of the PCA-DEA evaluation of the operational efficiency of the iron ore logistics at the ports of Bohai Bay, China.

PCA can reduce the dimensionality of the correlated original evaluation indicators through linear transformation while minimizing the information loss. The original multidimensional variables are replaced by several synthetic variables that are mutually independent. In this manner, the subjectivity of and the interference from the original indicators can be reduced. Therefore, the input and output indicators for the DEA method are mutually independent synthetic indicators. This property ensures the objectivity and accuracy of the evaluation results. In this study, the integrated PCA-DEA model is adopted to evaluate the operational efficiency of the iron ore logistics at the ports of Bohai Bay, China [39]. The evaluation framework is shown in Figure 1.
3.2.1. Steps of the Evaluation Using the PCA-DEA Model. The PCA and DEA methods are combined to form the integrated model used to evaluate the operational efficiency of the iron ore logistics at the ports of Bohai Bay. First, feature extraction is conducted for the original indicators using the PCA submodel. The indicators with large weight-to-port logistics efficiency are screened. The indicators obtained by feature extraction are the input and output indicators of the DEA model, which is mainly used to improve the unreasonable input and output indicators [39]. The procedures for the efficiency evaluation using the PCA-DEA integrated model are as follows.

(1) Normalization of the original indicators. 
Suppose the existence of $n$ samples, each of which contains $p$ variables. An $(n \times p)$ th-order data matrix is then formed and expressed as follows:

$$
X=\left[\begin{array}{cccc}
X_{11} & X_{12} & \cdots & X_{1 p} \\
X_{21} & X_{22} & \cdots & X_{2 p} \\
\vdots & \vdots & \vdots & \vdots \\
X_{n 1} & X_{n 2} & \cdots & X_{n p}
\end{array}\right]
$$

that is, $X=\left(X_{i j}\right), i=1,2, \ldots, n ; j=1,2, \ldots, p$.

The normalization of the indicator data can remove the influence of dimensionality on the different indicators. The normalization formula is written as

$$
X_{i j}^{*}=\frac{X_{i j}-\bar{X}_{j}}{\delta_{j}},
$$

where $\bar{X}_{j}=(1 / n) \sum_{i=1}^{n} X_{i j}$ is the sample mean and $\delta_{j}=$ $(1 /(n-1)) \sum_{i=1}^{n}\left(X_{i j}-\bar{X}_{j}\right)^{2}$ is the sample variance.

(2) The matrix $R$ of the correlation coefficients of the samples is established based on the indicator data. The characteristic value and characteristic vector of $R$ are calculated. Consider

$$
R=\left[\begin{array}{cccc}
r_{11} & r_{12} & \cdots & r_{1 p} \\
r_{21} & r_{22} & \cdots & r_{2 p} \\
\vdots & \vdots & \vdots & \vdots \\
r_{p 1} & r_{p 2} & \cdots & r_{p p}
\end{array}\right]
$$

where $r_{i j}(i, j=1,2, \ldots, p)$ is the correlation coefficient between the original variables $x_{i}$ and $x_{j} . R$ is the real symmetric matrix; that is, $r_{i j}=r_{j i}$. Only the upper or lower triangular elements can be calculated using the following formula:

$$
r_{i j}=\frac{\sum_{k=1}^{n}\left(X_{k i}-\bar{X}_{i}\right)\left(X_{k j}-\bar{X}_{j}\right)}{\sqrt{\sum_{k=1}^{n}\left(X_{k i}-\bar{X}_{i}\right)^{2} \sum_{k=1}^{n}\left(X_{k j}-\bar{X}_{j}\right)^{2}}} .
$$

The characteristic equation $|\lambda I-R|=0$ is solved. The characteristic values obtained are ranked by magnitude: $\lambda_{1} \geq$ $\lambda_{2} \geq \cdots \geq \lambda_{p} \geq 0$. Then, the characteristic vector $l_{i}(i=$ $1,2, \ldots, p)$ corresponding to the characteristic value $\lambda_{i}$ is calculated. The calculation requires that $\left\|l_{i}\right\|=1$; that is, $\sum_{j=1}^{p} l_{i j}^{2}=1$, where $l_{i j}$ is the $j$ th component of vector $l_{i}$.

(3) The contribution rate of each principal component and accumulative contribution rate are calculated.

The formula of the contribution rate is

$$
\frac{\lambda_{i}}{\sum_{k=1}^{p} \lambda_{k}} \quad(i=1,2, \ldots, p) .
$$

The formula of the accumulative contribution rate is

$$
\frac{\sum_{k=1}^{i} \lambda_{k}}{\sum_{k=1}^{p} \lambda_{k}} \quad(i=1,2, \ldots, p) \text {. }
$$

The first, second, and $m$ th $(m \leq p)$ principal components corresponding to the characteristic values $\lambda_{1}, \lambda_{2}, \ldots, \lambda_{m}$ with an accumulative contribution rate of approximately $85 \%$ are selected.

(4) For the analysis of the principal components, the relatively important indicators for the evaluation of the iron ore logistics of the ports are selected. These indicators are the input and output indicators to be used in the DEA model. Given that the input and output values of the DEA model should not be negative, $e(\approx 2.7183)$ is used as the base number, and power transform is conducted on the PCA results. As such, all the input and output indicators are positive.

(5) The data on the principal components of the indicators are introduced into the $\mathrm{C}^{2} \mathrm{R}$-DEA model. The optimal solutions $\theta^{0}, \lambda_{j}^{0}, S_{i}^{0-}$, and $S_{r}^{0+}$ are solved. Based on the solutions of the DEA model, the relative, scale, and technology efficiencies of the iron ore logistics operation of the ports are calculated. The units that fail to reach the DEA efficiency should be regulated.

3.2.2. Analysis Based on the DEA Method. After the PCA of the indicators of the operational efficiency of iron ore logistics, the principal indicators are formed into synthetic indicators, which are then subjected to the DEA method. DEA is a tool for evaluating the relative efficiency of the performance of similar schemes based on linear programming. Grounded in the concept of relative efficiency, the DEA method is especially suitable for the relative efficiency evaluation of DMUs involving multiple input and output indicators [40].

Suppose that $n$ DMUs exist. The synthetic indicator is composed of $s$ input indicators and $t$ output indicators. That is, each DMU has $s$ types of input indicators and $t$ types of output indicators denoted by $X_{j}$ and $Y_{j}$, respectively:

$$
\begin{gathered}
X_{j}=\left(X_{1 j}, X_{2 j}, \ldots, X_{s j}\right)^{T}, \\
Y_{j}=\left(Y_{1 j}, Y_{2 j}, \ldots, Y_{t j}\right)^{T},
\end{gathered}
$$

where $X_{i j} \geq 0$ is the $j$ th type of the input quantity of the $j$ th DMU $D M U_{j} ; Y_{r j} \geq 0$ is the $j$ th type of the output quantity of the $j$ th DMU DMU $j i=1,2, \ldots, s, r=1,2, \ldots, t, j=$ $1,2, \ldots, n$. For $D M U_{j_{0}}, X_{0}=X_{j_{0}}, Y_{0}=Y_{j_{0}}$, and $j_{0} \in[1, n]$. The $C^{2} \mathrm{R}$-DEA model $\left(D_{\mathrm{C}^{2} \mathrm{R}}^{\varepsilon}\right)$, which was proposed by Cooper et al. and has a non-Archimedean infinitesimal quantity $\mathcal{\varepsilon}$, is used $[40,41]$. One has

$$
\begin{gathered}
\operatorname{Min}\left[\theta-\varepsilon\left(\sum_{i=1}^{s} S_{i}^{-}+\sum_{r=1}^{t} S_{r}^{+}\right)\right] \\
\sum_{j=1}^{n} x_{i j} \lambda_{j}+S_{i}^{-}-\theta x_{i j_{0}}=0, \quad i=1,2, \ldots, s,
\end{gathered}
$$$$
\sum_{j=1}^{n} y_{r j} \lambda_{j}-S_{r}^{+}=y_{r j_{0}}, \quad r=1,2, \ldots, t,
$$ 


$$
\begin{aligned}
& \lambda_{j} \geq 0, \quad j=1,2, \ldots, n, \\
& S_{i}^{-} \geq 0, \quad i=1,2, \ldots, s, \\
& S_{r}^{+} \geq 0, \quad r=1,2, \ldots, t
\end{aligned}
$$

where $\lambda_{j}$ is the weight and $S_{i}^{-}$and $S_{r}^{+}$are the slack variables of the input and output, respectively. The positive number $\varepsilon$ results in the optimal solution $\theta^{0} . \lambda_{j}^{0}(j=1,2, \ldots, n)$ of the $D_{\mathrm{C}^{2} \mathrm{R}}$ model satisfies $\theta^{0}=1, S_{i}^{0-}=0$, and $S_{r}^{0+}=$ 0 . Then, $D M U_{j_{0}}$ reaches the DEA efficiency. $\varepsilon=10^{-6}$ is considered during calculation. The optimal solution to the linear programming model is solved as $\theta^{0}, \lambda_{j}^{0}, S_{i}^{0-}$, and $S_{r}^{0+}$. DEA efficiency and its economic significance are analyzed based on the values of the solution. We determine whether the logistics operation of the port has technology and scale efficiencies. The following conclusions are obtained [40].

(1) If $\theta^{0}=1, S_{i}^{0-}=0$, and $S_{r}^{0+}=0$, then the DMU $D M U_{j_{0}}$ has DEA efficiency. Moreover, the logistics activity of DMU $D M U_{j_{0}}$ has technology and scale efficiencies. The resources are fully utilized, and the input elements have the optimal combination. Thus, the maximum output effect is achieved.

(2) If $\theta^{0}=1$ and the slack variable of either input or output is larger than 0 , that is, $S_{i}^{0-}>0$ or $S_{r}^{0+}>0$, then the DMU $D M U_{j_{0}}$ has weak DEA efficiency. At this point, DMU $D M U_{j_{0}}$ does not have technology and scale efficiencies simultaneously. If $S_{i}^{0-}>0$, then the $i$ th type of the input indicator $S_{i}^{0-}$ is not fully utilized. If $S_{r}^{0+}>0$, then $S_{r}^{0+}$ difference exists between the $r$ th type of the output indicator and the optimal output value.

(3) If $\theta^{0}<1$, then the DMU DMU $j_{0}$ does not achieve DEA efficiency. Economic significance is manifested as logistics activities of DMU DMU $j_{j_{0}}$ that have neither optimal technology efficiency nor optimal scale efficiency.

In addition, the optimal solutions $\theta^{0}$ and $\lambda_{j}^{0}(j=1,2$, $\ldots, n)$ of $\theta$ and $\lambda_{j}$ of the $D_{\mathrm{C}^{2} \mathrm{R}}^{\varepsilon}$ model are usually used to determine the scale efficiency of the DMU. The following conclusions are obtained [40]:

(1) If $\left(1 / \theta^{0}\right) \sum_{j=1}^{n} \lambda_{j}^{0}=1$, then the scale benefit of the DMU stays constant.

(2) If $\left(1 / \theta^{0}\right) \sum_{j=1}^{n} \lambda_{j}^{0}<1$, then the scale benefit of the DMU increases progressively.

(3) If $\left(1 / \theta^{0}\right) \sum_{j=1}^{n} \lambda_{j}^{0}>1$, then the scale benefit of the DMU decreases progressively.

DEA is based on the concept of relative efficiency. As such, DEA is suitable for relative efficiency evaluation involving multiple input and output indicators. The DEA model uses the optimization tool and takes the weight coefficients of multiple input and output indicators as the decision variables. The evaluation is conducted in the optimal sense. Thus, the determination of the weight coefficient of the indicator in the statistical sense is avoided. In this case, the DEA method has intrinsic objectivity. Without making any assumption on weight, the optimal weight is calculated based on the actual input and output of the DMU. Therefore, the subjective factors are excluded. In the DEA model, the input and output are mutually correlated and restricted. Each input is correlated to one or several outputs.

\section{Empirical Study on the Evaluation of the Operational Efficiency of the Iron Ore Logistics in Bohai Bay}

Bohai Bay is the major steel production base in China and occupies a pivotal status in the steel industry in the country. Many national key steel enterprises, including Shoudu Iron and Steel Company, Anshan Steel, Tangshan Steel, Handan Steel, Baotou Steel, Tonghua Steel, Benxi Steel, and Jixi Steel, are located in this region. These enterprises have a high demand for iron ore and rely on the port logistics services in Bohai Bay for the trade and transport of iron ore. According to the Plan of Coastal Port Layout released by the Ministry of Communication of the People's Republic of China in 2006, China has five major port clusters, namely, Bohai Bay, Yangtze River Delta, southeast coastal region of China, Pearl River Delta, and southwest coastal region of China. Such division is based on the economic development features, current status of the port, transport between ports, and economic rationality of the transport of main commodities. The general layout consists of eight major logistics systems, namely, coal, oil, iron ore, container, food, automobiles, roll-on and rolloff transport, and passenger transport. The iron ore transport system is located near the steel enterprises, with the arrangement of professional berth being 200-300 tons. The iron ore logistics service system is equipped with the infrastructures for secondary unloading and transfer. The port cluster in Bohai Bay is composed of port clusters in Liaoning, Tianjin, Hebei, and the coastal regions of Shandong. This cluster mainly serves the social and economic development of the coastal region of north and inland China. The layout in Bohai Bay is dominated by three hub ports (Dalian, Tianjin, and Qingdao) and supplementary unloading ports in Yingkou, Tangshan, Rizhao, and Yantan. Seven iron ore logistics ports in Dalian, Yingkou, Tianjin, Rizhao, Tangshan, Qingdao, and Yantai in Bohai Bay are selected as the samples. The operational efficiency of iron ore logistics is comparatively studied.

4.1. PCA of the Evaluation Indicators of the Operational Efficiency of the Iron Ore Logistics of Ports. As indicated in the analysis presented previously, the number of input and output indicators should be reasonable when the DEA model is used for evaluation. Given that the original data contain overlapping information, the accuracy of the analysis result will be affected. First, PCA is conducted to transform the original data into several mutually independent indicators that preserve most of the information in the original data. China Port Yearbook 2012-2013 and China Statistical Yearbook 2012-2013 are the sources of the original data for the evaluation of the operational efficiency of the iron ore logistics in Bohai Bay. The PCA model is used (Steps (1) to (4)). Using the Statistical Package for the Social Sciences 
TABLE 2: Results of the normalization of the original input and output indicator data.

\begin{tabular}{|c|c|c|c|c|c|c|c|c|}
\hline Indicator & & Dalian & Yingkou & Tianjin & Rizhao & Tangshan & Qingdao & Yantai \\
\hline \multirow{11}{*}{ Input indicator } & $X_{1}$ & -0.107 & 1.422 & -0.141 & 0.063 & -1.363 & 1.082 & -0.956 \\
\hline & $X_{2}$ & 0.832 & -1.160 & -0.547 & 0.985 & -0.547 & 1.291 & -0.853 \\
\hline & $X_{3}$ & 0.637 & -0.106 & 0.637 & -0.850 & 1.381 & -1.593 & -0.106 \\
\hline & $X_{4}$ & -0.691 & -0.530 & -0.350 & 1.020 & 1.802 & -0.469 & -0.782 \\
\hline & $X_{5}$ & -0.672 & -0.491 & -0.491 & 2.041 & 0.052 & 0.413 & -0.853 \\
\hline & $X_{6}$ & -0.586 & 0.098 & -0.586 & -0.586 & 2.147 & 0.098 & -0.586 \\
\hline & $X_{7}$ & -0.817 & -0.209 & -0.596 & 1.174 & 1.423 & 0.239 & -1.215 \\
\hline & $X_{8}$ & -0.671 & 0.334 & -0.584 & -0.431 & 0.553 & 1.864 & -1.064 \\
\hline & $X_{9}$ & 0.260 & -0.188 & -0.531 & -0.814 & 0.135 & 2.033 & -0.895 \\
\hline & $X_{10}$ & -0.365 & -0.635 & 1.010 & -0.111 & 1.751 & -0.866 & -0.783 \\
\hline & $X_{11}$ & -0.621 & -0.562 & 2.029 & -0.651 & 0.272 & 0.302 & -0.770 \\
\hline \multirow{4}{*}{ Output indicator } & $Y_{1}$ & -0.917 & -0.730 & -0.577 & 1.178 & 0.968 & 1.030 & -0.953 \\
\hline & $Y_{2}$ & -0.790 & 1.861 & -0.868 & 0.870 & -0.381 & -0.433 & -0.260 \\
\hline & $Y_{3}$ & -0.029 & 0.213 & -0.164 & 1.710 & -0.864 & 0.536 & -1.403 \\
\hline & $Y_{4}$ & 0.565 & -0.859 & 0.881 & -0.226 & -0.226 & 1.356 & -1.492 \\
\hline
\end{tabular}

TABLE 3: Matrix of the correlation coefficients of the input indicators (correlation matrix).

\begin{tabular}{cccccccccccc}
\hline & $X_{1}$ & $X_{2}$ & $X_{3}$ & $X_{4}$ & $X_{5}$ & $X_{6}$ & $X_{7}$ & $X_{8}$ & $X_{9}$ & $X_{10}$ & $X_{11}$ \\
\hline$X_{1}$ & 1.000 & 0.227 & -0.644 & -0.464 & 0.127 & -0.336 & -0.095 & 0.480 & 0.433 & -0.598 & -0.061 \\
$X_{2}$ & 0.227 & 1.000 & -0.542 & 0.052 & 0.587 & -0.234 & 0.269 & 0.327 & 0.540 & -0.273 & -0.120 \\
$X_{3}$ & -0.644 & -0.542 & 1.000 & 0.307 & -0.487 & 0.435 & -0.027 & -0.427 & -0.403 & 0.742 & 0.248 \\
$X_{4}$ & -0.464 & 0.052 & 0.307 & 1.000 & 0.591 & 0.707 & 0.914 & 0.168 & -0.122 & 0.716 & 0.051 \\
$X_{5}$ & 0.127 & 0.587 & -0.487 & 0.591 & 1.000 & 0.015 & 0.758 & 0.233 & 0.021 & 0.039 & -0.139 \\
$X_{6}$ & -0.336 & -0.234 & 0.435 & 0.707 & 0.015 & 1.000 & 0.651 & 0.502 & 0.272 & 0.627 & 0.094 \\
$X_{7}$ & -0.095 & 0.269 & -0.027 & 0.914 & 0.758 & 0.651 & 1.000 & 0.474 & 0.159 & 0.489 & 0.008 \\
$X_{8}$ & 0.480 & 0.327 & -0.427 & 0.168 & 0.233 & 0.502 & 0.474 & 1.000 & 0.873 & -0.054 & 0.143 \\
$X_{9}$ & 0.433 & 0.540 & -0.403 & -0.122 & 0.021 & 0.272 & 0.159 & 0.873 & 1.000 & -0.208 & 0.123 \\
$X_{10}$ & -0.598 & -0.273 & 0.742 & 0.716 & 0.039 & 0.627 & 0.489 & -0.054 & -0.208 & 1.000 & 0.587 \\
$X_{11}$ & -0.061 & -0.120 & 0.248 & 0.051 & -0.139 & 0.094 & 0.008 & 0.143 & 0.123 & 0.587 & 1.000 \\
\hline
\end{tabular}

(SPSS) 19.0, calculation and PCA are conducted for the indicator data of the seven major ports.

The original data are normalized using SPSS 19.0. Next, 11 input indicators and 4 output indicators are subjected to normalization to remove the influence of dimensionality. The specific results are listed in Table 2.

The correlation coefficients of indicator and the data are analyzed using SPSS. The matrices of the correlation coefficients of the input and output indicators are real symmetric matrices (Tables 3 and 4). A large correlation coefficient indicates a strong correlation among the variables. Thus, more overlapping information will be obtained. Tables 3 and 4 show a number of overlapped indicator data. According to the correlation coefficient in Tables 3 and 4, some variables have strong correlation. For example, $X_{1}$ has strong negative correlation with $X_{3}$ and $X_{10}$, with the correlation coefficient of -0.644 and -0.598 , respectively; $X_{3}$ and $X_{10}$ have strong positive correlation, with the correlation coefficient as high as $0.742 ; X_{4}$ has very strong positive correlation with $X_{6}, X_{7}$, and $X_{10}$, with the correlation coefficient reaching $0.707,0.914$, and 0.716 , respectively; the positive correlation coefficient of $X_{8}$ and $X_{9}$ also reaches up to 0.873 ; furthermore, the output
TABle 4: Matrix of the correlation coefficients of the output indicators (correlation matrix).

\begin{tabular}{ccccc}
\hline & $Y_{1}$ & $Y_{2}$ & $Y_{3}$ & $Y_{4}$ \\
\hline$Y_{1}$ & 1.000 & 0.073 & 0.520 & 0.353 \\
$Y_{2}$ & 0.073 & 1.000 & 0.485 & -0.281 \\
$Y_{3}$ & 0.520 & 0.485 & 1.000 & 0.260 \\
$Y_{4}$ & 0.353 & -0.281 & 0.260 & 1.000 \\
\hline
\end{tabular}

variable $Y_{3}$ also has obvious positive correlation with output variables $Y_{1}$ and $Y_{2}$, with the correlation coefficient of 0.520 and 0.485 , respectively. Other variables also have similar correlation. In order to reduce the information interference between these variables, it is necessary to extract the principal components of all relevant indexes.

SPSS 19.0 is used for the extraction of the principal components of all input and output indicators. Of the 11 input indicators, 4 principal components are obtained. The accumulative contribution rate of these four principal components reaches approximately $91 \%$. Of the four output 
TABLE 5: Component matrix of the input and output indicators.

\begin{tabular}{|c|c|c|c|c|c|c|c|}
\hline \multirow{2}{*}{ Indicator } & \multicolumn{4}{|c|}{ Load of the principal components of the input indicators } & \multirow{2}{*}{ Indicator } & \multicolumn{2}{|c|}{ Load of the principal components of the output indicators } \\
\hline & 1 & 2 & 3 & 4 & & 1 & 2 \\
\hline$X_{1}$ & -0.694 & 0.378 & 0.219 & 0.022 & $Y_{1}$ & 0.794 & -0.253 \\
\hline$X_{2}$ & -0.326 & 0.660 & -0.250 & 0.307 & $Y_{2}$ & 0.431 & 0.830 \\
\hline$X_{3}$ & 0.727 & -0.554 & 0.194 & -0.063 & $Y_{3}$ & 0.893 & 0.216 \\
\hline$X_{4}$ & 0.843 & 0.443 & -0.296 & -0.054 & $Y_{4}$ & 0.469 & -0.747 \\
\hline$X_{5}$ & 0.107 & 0.722 & -0.631 & 0.221 & & & \\
\hline$X_{6}$ & 0.753 & 0.354 & 0.363 & -0.418 & & & \\
\hline$X_{7}$ & 0.598 & 0.749 & -0.229 & -0.054 & & & \\
\hline$X_{8}$ & -0.060 & 0.823 & 0.534 & -0.143 & & & \\
\hline$X_{9}$ & -0.276 & 0.676 & 0.603 & -0.048 & & & \\
\hline$X_{10}$ & 0.941 & -0.038 & 0.153 & 0.288 & & & \\
\hline$X_{11}$ & 0.310 & -0.041 & 0.532 & 0.766 & & & \\
\hline
\end{tabular}

TABLE 6: Characteristic vectors of the input and output indicators (column vector).

\begin{tabular}{|c|c|c|c|c|c|c|c|}
\hline \multirow{2}{*}{ Indicator } & \multicolumn{4}{|c|}{ Characteristic vector of the input indicators } & \multirow{2}{*}{ Indicator } & \multicolumn{2}{|c|}{ Characteristic vector of the output indicator } \\
\hline & 1 & 2 & 3 & 4 & & 1 & 2 \\
\hline$X_{1}$ & -0.355 & 0.204 & 0.165 & 0.022 & $Y_{1}$ & 0.593 & 0.063 \\
\hline$X_{2}$ & -0.167 & 0.357 & -0.188 & 0.304 & $Y_{2}$ & 0.039 & 0.789 \\
\hline$X_{3}$ & 0.372 & -0.299 & 0.146 & -0.062 & $Y_{3}$ & 0.626 & 0.314 \\
\hline$X_{4}$ & 0.431 & 0.239 & -0.222 & -0.053 & $Y_{4}$ & 0.505 & -0.524 \\
\hline$X_{5}$ & 0.055 & 0.390 & -0.474 & 0.219 & & & \\
\hline$X_{6}$ & 0.385 & 0.191 & 0.273 & -0.414 & & & \\
\hline$X_{7}$ & 0.306 & 0.405 & -0.172 & -0.053 & & & \\
\hline$X_{8}$ & -0.031 & 0.445 & 0.401 & -0.142 & & & \\
\hline$X_{9}$ & -0.141 & 0.365 & 0.453 & -0.048 & & & \\
\hline$X_{10}$ & 0.481 & -0.021 & 0.115 & 0.285 & & & \\
\hline$X_{11}$ & 0.158 & -0.022 & 0.400 & 0.758 & & & \\
\hline
\end{tabular}

indicators, two principal components are obtained. Their accumulative contribution rate reaches approximately $85 \%$. The loads of the principal components of the input and output indicators are shown in Table 5. The characteristic vectors of the matrices are determined based on the loads of the principal components and the characteristic values of the matrices of the correlation coefficients in Table 5 (see Table 6).

The characteristic vectors in Table 6 correspond to the coefficient of each principal indicator. Using the data in Table 6, the formula of the synthetic indicators of the operational efficiency of the iron ore logistics at the ports of Bohai Bay can be expressed as follows.

For the input indicators (four principal components denoted as $I_{1}, I_{2}, I_{3}$, and $I_{4}$ ),

$$
\begin{aligned}
I_{1}= & -0.355 X_{1}-0.167 X_{2}+0.372 X_{3}+0.431 X_{4} \\
& +0.055 X_{5}+0.385 X_{6}+0.306 X_{7}-0.031 X_{8} \\
& -0.141 X_{9}+0.481 X_{10}+0.158 X_{11},
\end{aligned}
$$

$$
\begin{aligned}
I_{2}= & 0.204 X_{1}+0.357 X_{2}-0.299 X_{3}+0.239 X_{4} \\
& +0.390 X_{5}+0.191 X_{6}+0.405 X_{7}+0.445 X_{8} \\
& +0.365 X_{9}-0.021 X_{10}-0.022 X_{11}, \\
I_{3}= & 0.165 X_{1}-0.188 X_{2}+0.146 X_{3}-0.222 X_{4} \\
& -0.474 X_{5}+0.273 X_{6}-0.172 X_{7}+0.401 X_{8} \\
& +0.453 X_{9}+0.115 X_{10}+0.400 X_{11}, \\
I_{4}= & 0.022 X_{1}+0.304 X_{2}-0.062 X_{3}-0.053 X_{4} \\
& +0.219 X_{5}-0.414 X_{6}-0.053 X_{7}-0.142 X_{8} \\
& -0.048 X_{9}+0.285 X_{10}+0.758 X_{11} .
\end{aligned}
$$

For the output indicators (two principal components denoted as $o_{1}$ and $o_{2}$ ),

$$
\begin{aligned}
& o_{1}=0.593 Y_{1}+0.039 Y_{2}+0.626 Y_{3}+0.505 Y_{4}, \\
& o_{2}=0.063 Y_{1}+0.789 Y_{2}+0.314 Y_{3}-0.524 Y_{4} .
\end{aligned}
$$


TABLE 7: Values of the principal components of the input and output indicators.

\begin{tabular}{lcccccc}
\hline \multirow{2}{*}{ Port samples } & \multicolumn{3}{c}{ Principal components of the input indicators } & \multicolumn{3}{c}{ Principal components of the output indicators } \\
& $I_{1}$ & $I_{2}$ & $I_{3}$ & $I_{4}$ & -0.308 & $o_{2}$ \\
\hline Dalian & -0.964 & -0.968 & -0.070 & -0.106 & -0.659 & 1.941 \\
Yingkou & -1.011 & -0.370 & 0.601 & -1.068 & -0.034 & -1.235 \\
Tianjin & 0.693 & -1.562 & 0.878 & 1.910 & 0.690 & 1.417 \\
Rizhao & 0.154 & 1.550 & -2.669 & 0.499 & -0.096 & -0.393 \\
Tangshan & 3.979 & 0.804 & 0.588 & -0.710 & 1.614 & -0.820 \\
Qingdao & -1.973 & 2.905 & 1.287 & 0.199 & -2.207 & 0.077 \\
Yantai & -0.879 & -2.358 & -0.615 & -0.725 & & $o_{2}$ \\
\hline
\end{tabular}

TABLE 8: Negative-to-positive transform of the principal components of the input and output indicators.

\begin{tabular}{|c|c|c|c|c|c|c|}
\hline \multirow{2}{*}{ Port sample } & \multicolumn{4}{|c|}{ Principal components of the input indicators } & \multicolumn{2}{|c|}{ Principal components of the output indicators } \\
\hline & $I_{1}$ & $I_{2}$ & $I_{3}$ & $I_{4}$ & $o_{1}$ & $o_{2}$ \\
\hline Dalian & 0.381 & 0.380 & 0.933 & 0.900 & 0.607 & 0.445 \\
\hline Yingkou & 0.364 & 0.691 & 1.823 & 0.344 & 1.301 & 5.196 \\
\hline Tianjin & 2.000 & 0.210 & 2.406 & 6.755 & 0.532 & 0.735 \\
\hline Rizhao & 1.166 & 4.709 & 0.069 & 1.648 & 5.758 & 3.430 \\
\hline Tangshan & 53.441 & 2.234 & 1.801 & 0.492 & 1.235 & 0.314 \\
\hline Qingdao & 0.139 & 18.265 & 3.621 & 1.220 & 3.547 & 0.299 \\
\hline Yantai & 0.415 & 0.095 & 0.541 & 0.484 & 0.094 & 1.826 \\
\hline
\end{tabular}

The normalized data of the input and output indicators in Table 2 are substituted into Formulas (9) and (10). Thus, the values of the principal components of the indicators are obtained (Table 7).

Given that the input and output values of the DEA model should not be negative, $e(\approx 2.7183)$ is used as the base number, and power transform is conducted on the PCA results. The results of the negative-to-positive transform of the principal components of the input and output indicators are shown in Table 8. The nonnegative data of the principal components in Table 8 are analyzed using the DEA model.

4.2. DEA Evaluation of the Operational Efficiency of the Iron Ore Logistics. $I_{1}, I_{2}, I_{3}$, and $I_{4}$ are the input variables, and $o_{1}$ and $o_{2}$ are the output variables. The DEA model shown in Formula (8) is used to evaluate the operational efficiency of the iron ore logistics at the ports of Bohai Bay. In the DEA model, the number of $D M U$ is $7, s=4$, and $t=2$. All the values of the input and output indicators are transformed into positive values to form the synthetic indicators. We take the DMU DMU of Dalian Port as an example. The formula is expressed as follows based on the input and output data:

$$
\begin{aligned}
& \operatorname{Min}\left[\theta-10^{-6}\left(s_{1}^{-}+s_{2}^{-}+s_{3}^{-}+s_{4}^{-}+s_{1}^{+}+s_{2}^{+}\right)\right] \\
& 0.381 \lambda_{1}+0.364 \lambda_{2}+2 \lambda_{3}+1.166 \lambda_{4}+53.441 \lambda_{5} \\
& \quad+0.139 \lambda_{6}+0.415 \lambda_{7}+s_{1}^{-}-0.381 \theta=0, \\
& 0.380 \lambda_{1}+0.691 \lambda_{2}+0.210 \lambda_{3}+4.709 \lambda_{4}+2.234 \lambda_{5} \\
& \quad+18.265 \lambda_{6}+0.095 \lambda_{7}+s_{2}^{-}-0.380 \theta=0,
\end{aligned}
$$

$$
\begin{aligned}
& 0.933 \lambda_{1}+1.823 \lambda_{2}+2.406 \lambda_{3}+0.069 \lambda_{4}+1.801 \lambda_{5} \\
& \quad+3.261 \lambda_{6}+0.541 \lambda_{7}+s_{3}^{-}-0.933 \theta=0, \\
& 0.900 \lambda_{1}+0.344 \lambda_{2}+6.755 \lambda_{3}+1.648 \lambda_{4}+0.492 \lambda_{5} \\
& \quad+1.22 \lambda_{6}+0.484 \lambda_{7}+s_{4}^{-}-0.900 \theta=0, \\
& 0.607 \lambda_{1}+1.301 \lambda_{2}+0.532 \lambda_{3}+5.758 \lambda_{4}+1.235 \lambda_{5} \\
& \quad+3.547 \lambda_{6}+0.094 \lambda_{7}-s_{1}^{+}=0.607, \\
& 0.445 \lambda_{1}+5.196 \lambda_{2}+0.735 \lambda_{3}+3.43 \lambda_{4}+0.314 \lambda_{5} \\
& \quad+0.299 \lambda_{6}+1.826 \lambda_{7}-s_{2}^{+}=0.445, \\
& \lambda_{1}, \lambda_{2}, \lambda_{3}, \lambda_{4}, \lambda_{5}, \lambda_{6}, \lambda_{7} \geq 0, \\
& s_{1}^{-}, s_{2}^{-}, s_{3}^{-}, s_{4}^{-}, s_{1}^{+}, s_{2}^{+} \geq 0 .
\end{aligned}
$$

Similarly, the DEA models for the other six ports, namely, Yingkou, Tianjin, Rizhao, Tangshan, Qingdao, and Yantai, are established using the synthetic input and output indicators. The LINGO12.0 software is used to solve the previously presented linear programming models. The results of the DEA evaluation are shown in Table 9.

The DEA evaluation data shown in Table 9 are analyzed. With regard to DEA efficiency, for five DMUs (Yingkou, Tianjin, Rizhao, Qingdao, and Yantai ports), $\theta^{0}=1, S_{i}^{-}=0$ (where $i=1,2,3,4$ ), and $S_{r}^{+}=0$ (where $\left.r=1,2\right)$. Therefore, the five ports are DMUs with DEA efficiency. The input and output states of the five ports have technology and scale efficiencies. That is, the input and output states and efficiency 
TABLE 9: DEA-based evaluation of the operational efficiency of the iron ore logistics in Bohai Bay.

\begin{tabular}{lccccccccc}
\hline Port DMU & $\theta^{0}$ & $\sum \lambda^{0}$ & $\frac{1}{\theta^{0}} \sum \lambda^{0}$ & $S_{1}^{0-}$ & $S_{2}^{0-}$ & $S_{3}^{0-}$ & $S_{4}^{0-}$ & $S_{1}^{0+}$ & $S_{2}^{0+}$ \\
\hline Dalian & 0.86956 & 0.4496 & $<1$ & 0.1641 & 0 & 0 & 0.6213 & 0 \\
Yingkou & 1 & 1 & 1 & 0 & 0 & 0 & 0 & 0 \\
Tianjin & 1 & 1 & 1 & 0 & 0 & 0 & 0 & 0 \\
Rizhao & 1 & 1 & 1 & 0 & 0 & 0 & 0 & 0 \\
Tangshan & 0.67976 & 0.73216 & $>1$ & 36.0090 & 0.7589 & 0 & 0 & 0 \\
Qingdao & 1 & 1 & 1 & 0 & 0 & 0 & 0 & 0 \\
Yantai & 1 & 1 & 1 & 0 & 0 & 0 & 0 & 0 \\
\hline
\end{tabular}

TABLE 10: Efficiency of the DEA evaluation of the operational efficiency of the iron ore logistics in Bohai Bay.

\begin{tabular}{lccc}
\hline Port DMU & Relative efficiency & Scale efficiency & Technology efficiency \\
\hline Dalian & No DEA efficiency & Return to scale increases progressively & Inefficient \\
Yingkou & DEA efficiency & Unchanged scale benefit & Efficient \\
Tianjin & DEA efficiency & Unchanged return to scale & Efficient \\
Rizhao & DEA efficiency & Unchanged return to scale & Efficient \\
Tangshan & No DEA efficiency & Return to scale decreases progressively & Inefficient \\
Qingdao & DEA efficiency & Unchanged return to scale & Efficient \\
Yantai & DEA efficiency & Unchanged return to scale & Efficient \\
\hline
\end{tabular}

are optimal. For two DMUs (Dalian and Tangshan ports), $\theta^{0}<1$. As such, these ports achieve neither DEA efficiency nor technology efficiency.

With regard to the return to scale, $\theta^{0}=1$ for five DMUs (Yingkou, Tianjin, Rizhao, Qingdao, and Yantai ports). When $\sum \lambda^{0}=1$ and $\left(1 / \theta^{0}\right) \sum \lambda^{0}=1$, the return to scale remains unchanged. For the DMU of Dalian port, $\left(1 / \theta^{0}\right) \sum \lambda^{0}=$ $0.4496 / 0.8695=0.5170<1$, which means that the return to scale increases progressively. Thus, by increasing the input quantity for Dalian port, the output quantity will increase. For the DMU of Tangshan port, $\left(1 / \theta^{0}\right) \sum \lambda^{0}=0.7321 / 0.6797=$ $1.0771>1$, which means that the return to scale decreases progressively. This finding indicates that the excess input of the iron ore logistics operation in Tangshan port cannot fully enhance the output under the existing conditions. Table 10 shows the efficiency of the DEA evaluation of the operational efficiency of the iron ore logistics in Bohai Bay.

As shown in Tables 9 and 10, not all the DMUs of the ports achieve DEA efficiency. Some of these DMUs are analyzed to identify the reasons for their failure to achieve DEA efficiency and to provide references for improvement. Therefore, discussing the projection of the DMUs on the relative efficiency plane is necessary. The DMUs that fail to achieve DEA efficiency are transformed into those that do have DEA efficiency.

For $n$ DMUs of ports, the synthetic indicator is composed of $s$ input indicators and $t$ output indicators. $\theta^{0}, \lambda_{j}^{0}, S_{i}^{0-}$, and $S_{r}^{0+}$ are the optimal solutions of the linear programming of the $j$ th DMU DMU $U_{j}$ of a given port. We let $X^{\prime 0}=\theta^{0} X^{0}-S^{0-}$ and $Y^{\prime 0}=Y^{0}+S^{0+}$, where $\left(X^{\prime 0}, Y^{\prime 0}\right)$ is the projection of $\left(X^{0}, Y^{0}\right)$ corresponding to DMU DMU $j_{0}$ on the relative efficiency plane. This projection constitutes a new DMU of the given port. Then, the new DMU $\left(X^{\prime 0}, Y^{\prime 0}\right)$ has DEA efficiency in relation to the original $n$ DMU [40], where the input and output data corresponding to $\mathrm{DMU}_{j_{0}}$ are $X_{0}=X_{j_{0}}, Y_{0}=Y_{j_{0}}$, and $j_{0} \in[1, n]$; vector $S^{0-}=\left(S_{i}^{0-}\right), i=1,2, \ldots, s$; vector $S^{0+}=\left(S_{r}^{0+}\right), r=1,2, \ldots, t$. In this manner, projection analysis is conducted for the DMUs of the Dalian and Tangshan ports without DEA efficiency.

Then, the projection of the DMU of Dalian port on the relative efficiency plane is expressed as

$$
\begin{aligned}
X^{\prime 0}= & \theta^{0} X^{0}-S^{0-} \\
= & 0.8695(0.381,0.380,0.933,0.900) \\
& -(0.1641,0,0,0.6213) \\
= & (0.1672,0.3304,0.8113,0.1613) \\
Y^{\prime 0}= & Y^{0}+S^{0+}=(0.607,0.445)+(0,1.8825) \\
= & (0.6070,2.3275) .
\end{aligned}
$$

Similarly, the projection of the DMU of Tangshan port on the relative efficiency plane is expressed as

$$
\begin{aligned}
X^{\prime 0}= & \theta^{0} X^{0}-S^{0-} \\
= & 0.6797(53.441,2.234,1.801,0.492) \\
& -(36.0090,0.7589,0,0) \\
= & (0.3170,0.7597,1.2242,0.3344), \\
Y^{\prime 0}= & Y^{0}+S^{0+}=(1.2350,0.3140)+(0,3.3778) \\
= & (1.2350,3.6918) .
\end{aligned}
$$


According to Tables 9 and 10, the decision-making units of five ports, Yingkou Port, Tianjin Port, Rizhao Port, Qingdao Port, and Yantai Port, have achieved the best scale and efficiency and the production input of the five ports matches their efficiency output. In contrast, Dalian Port and Tangshan Port have large potential to improve their inputoutput efficiency. The projection analysis shows that Dalian Port and Tangshan Port failed to sufficiently utilize input resources and had a low output. If Dalian Port fully utilizes its resources, the output value can be increased from the former $(1.2350,0.3140)$ to $(1.2350,3.6918)$ while the input is only 0.87 times of the current input. Compared with ports with efficient DMU, Tangshan Port has a more serious problem in the utilization of input resources. After the improvement of utilization efficiency, the output value of Tangshan Port can be increased from the former $(1.2350,0.3140)$ to $(1.2350,3.6918)$ while the input is lowered by $32 \%$.

\section{Discussion and Conclusion}

The integrated PCA-DEA model is used in this study to analyze the evaluation method for the operational efficiency of the iron ore logistics in Bohai Bay, China. The comparison shows that the operational efficiency of the iron ore logistics of the different ports in this region presents varying features. The port authority and operating managers can implement corresponding port development strategies according to these results of efficiency evaluation.

The Qingdao, Tianjin, and Dalian ports are the three major hub ports in this region. However, only the Qingdao and Tianjin ports have iron ore logistics with high operational efficiency. These two ports have technology and scale efficiencies. Thus, these two ports are efficient DMUs. Therefore, considering the sound performance of Qingdao Port and Tianjin Port, the managers of the two ports should maintain the present operating scale and production mode so as to maintain relatively high production efficiency. The overall efficiency value of the iron ore logistics of Dalian port is less than 1 . Hence, the DMU is inefficient in terms of either technology efficiency or scale efficiency. This finding indicates the need for improvement in the operational efficiency of the iron ore logistics of Dalian port, which is one of the hub ports in the coastal region of North China. The projection analysis also reveals that the infrastructures of Dalian port fail to fulfill its functions to the maximum extent and thus cause resource wastage. The evaluation results show that the scale return of Dalian port increases progressively. For Dalian port, integrating the existing production resources and fully utilizing the infrastructures are necessary to address its lack of DEA efficiency. Furthermore, Dalian port has immense development potential. The scale of the port can be expanded by increasing the number of berths and improving the iron ore collection and distribution system. These measures are important to achieve optimal scale return.

Among the other ports, the Yingkou, Rizhao, and Yantai ports have iron ore logistics with high operational efficiency given their current scale. The overall iron ore logistics efficiency value is 1 , which indicates the DEA efficiency of these DMUs. The evaluation results indicate that these ports fully utilize their infrastructures and maximize their iron ore carrying capacities. Furthermore, the scale return of these ports remains unchanged. The current scale of the ports has already yielded the optimal benefits. Consequently, the management authority of Yingkou Port, Rizhao Port, and Yantai Port should maintain their current development pattern and keep the efficient functioning of iron ore logistics system, so as to better serve local social and economic development. Tangshan Port has iron ore logistics with low operational efficiency. The overall operational efficiency of its iron ore logistics is less than 1 . Hence, this DMU is inefficient in terms of either technology efficiency or scale efficiency. Projection analysis indicates that, unlike other effective DMUs, Tangshan Port cannot fully utilize its resources. The reason for the low efficiency of Tangshan Port is its failure to maximize the benefits of its infrastructures. The scale benefit of the operational efficiency of iron ore logistics of Tangshan Port decreases progressively. Even when Tangshan Port increases the input in its infrastructures, the benefits of port logistics barely increase. Therefore, the management staff of Tangshan Port should pay attention to and concentrate on improving the comprehensive service of iron ore logistics system of the port and the overall operational efficiency of the integrated logistics system. That means that the key tasks for Tangshan port is to enhance the coordination between the various links of its iron ore logistics and to fully utilize its port infrastructures.

This study mainly evaluates the iron ore ports of Bohai Bay, China, using the iron ore logistics data of these ports as data sources. PCA is utilized to extract the principal components of the original indicators, which are then taken as the input and output data of the DEA model. Iron ore logistics is evaluated using the DEA model. The relative efficiency of the DEA evaluation of the iron ore logistics of the ports is also determined. The PCA-DEA integrated model is deemed suitable for the evaluation of port logistics efficiency with high accuracy and practicability. Moreover, the findings of the present work provide theoretical and decision-making bases for the improvement of port logistics efficiency.

\section{Conflict of Interests}

The authors declare that there is no conflict of interests regarding the publication of this paper.

\section{Acknowledgments}

This study is supported by the National Natural Science Foundation of China (Grant nos. 51409157, 71473162, and 51508319), the Young Scholar Program of Humanities and Social Science of the Ministry of Education of China (14YJC630008), Shanghai Municipal Education Commission Project (14YZ109), TUP-GLS (Tong Myong Education Program for Next Generation Global Logistics Specialists), Shanghai Science \& Technology Committee Research Project (15590501700), and the fund of Shanghai Maritime University (20130457). 


\section{References}

[1] Y. Roll and Y. Hayuth, "Port performance comparison applying data envelopment analysis (DEA)," Maritime Policy \& Management, vol. 20, no. 2, pp. 153-161, 1993.

[2] J. Tongzon, "Efficiency measurement of selected Australian and other international ports using data envelopment analysis," Transportation Research Part A: Policy and Practice, vol. 35, no. 2, pp. 107-122, 2001.

[3] R. J. Sánchez, J. Hoffmann, A. Micco, G. V. Pizzolitto, M. Sgut, and G. Wilmsmeier, "Port efficiency and international trade: port efficiency as a determinant of maritime transport costs," Maritime Economics \& Logistics, vol. 5, no. 2, pp. 199-218, 2003.

[4] J. Tongzon and W. Heng, "Port privatization, efficiency and competitiveness: some empirical evidence from container ports (terminals)," Transportation Research-Part A: Policy and Practice, vol. 39, no. 5, pp. 405-424, 2005.

[5] Y.-C. J. Wu and C.-W. Lin, "National port competitiveness: implications for India," Management Decision, vol. 46, no. 10, pp. 1482-1507, 2008.

[6] R. Markovits-Somogyi, "Measuring efficiency in transport: the state of the art of applying data envelopment analysis," Transport, vol. 26, no. 1, pp. 11-19, 2011.

[7] A. Jarašūnienè, L. Greičiūnè, and A. Šakalys, "Research of competitive environment of Klaipeda Seaport comparing to other seaports in the eastern Baltic Sea region," Transport, vol. 27, no. 1, pp. 5-13, 2012.

[8] K. Cullinane, D.-W. Song, P. Ji, and T.-F. Wang, "An application of DEA windows analysis to container port production efficiency," Review of Network Economics, vol. 3, no. 2, pp. 1-23, 2004.

[9] Z. Q. Chen, X. P. Yan, and X. S. Cao, "The spatial characters and associated mechanism of port service industries in Guangzhou," Scientia Geographica Sinica, vol. 30, no. 1, pp. 31-37, 2010.

[10] C. J. Wang and C. Ducruet, "Theoretical model of container port system and its empirical research in Yangtze River Delta," Geographical Research, vol. 30, no. 3, pp. 397-409, 2011.

[11] S. Liang, Y. Cao, and W. Wu, "Spatial pattern evolution of port logistics enterprises in Shanghai metropolitan area," Geographical Research, vol. 32, no. 8, pp. 1448-1456, 2013.

[12] L. I. Lan, L. Jun, and L. Chun, "Analysis of dynamic efficiency of main ports in mainland China, Hongkong and Taiwan-based on DEA-malmquist productivity index," Soft Science, vol. 25, no. 5, pp. 80-84, 2011.

[13] C. Z. Sun and S. Xiao, "Relative efficiency evaluation of the port economy in the coastal provinces and cities based on DEA method," Areal Research and Development, vol. 28, no. 1, pp. 3236, 2009.

[14] L. Tan, W. Li, and W. Yu, "Research on synergetic development between efficiency of port logistics and its hinterland economy in Liaoning Province," Economic Geography, vol. 32, no. 9, pp. 108-113, 2012.

[15] D.-S. Li, S.-Z. Zhang, and L.-F. Yuan, "Research on measurement of comprehensive efficiency for port logistics," Journal of Transportation Systems Engineering and Information Technology, vol. 13, no. 5, pp. 107-113, 2013.

[16] T. Lee, G.-T. Yeo, and V. V. Thai, "Environmental efficiency analysis of port cities: slacks-based measure data envelopment analysis approach," Transport Policy, vol. 33, pp. 82-88, 2014.

[17] A. C.-L. Yuen, A. Zhang, and W. Cheung, "Foreign participation and competition: a way to improve the container port efficiency in China?" Transportation Research-Part A: Policy and Practice, vol. 49, pp. 220-231, 2013.

[18] D. Pjevčević, A. Radonjić, Z. Hrle, and V. Čolić, "DEA window analysis for measuring port efficiencies in Serbia," PROMETTraffice Transportation, vol. 24, no. 1, pp. 63-72, 2012.

[19] D. Aigner, C. A. Lovell, and P. Schmidt, "Formulation and estimation of stochastic frontier production function models," Journal of Econometrics, vol. 6, no. 1, pp. 21-37, 1977.

[20] K. Cullinane, D.-W. Song, and R. Gray, "A stochastic frontier model of the efficiency of major container terminals in Asia: assessing the influence of administrative and ownership structures," Transportation Research Part A: Policy and Practice, vol. 36, no. 8, pp. 743-762, 2002.

[21] K. Cullinane, T.-F. Wang, D.-W. Song, and P. Ji, “The technical efficiency of container ports: comparing data envelopment analysis and stochastic frontier analysis," Transportation Research Part A: Policy and Practice, vol. 40, no. 4, pp. 354-374, 2006.

[22] M. M. González and L. Trujillo, "Reforms and infrastructure efficiency in Spain's container ports," Transportation ResearchPart A: Policy and Practice, vol. 42, no. 1, pp. 243-257, 2008.

[23] Y.-C. J. Wu and M. Goh, "Container port efficiency in emerging and more advanced markets," Transportation Research-Part E: Logistics and Transportation Review, vol. 46, no. 6, pp. 10301042, 2010.

[24] H. Yang, K. Lin, O. R. Kennedy, and B. Ruth, "Sea-port operational efficiency: an evaluation of five Asian ports using stochastic frontier production function model," Journal of Service Science and Management, vol. 4, no. 3, pp. 391-399, 2011.

[25] M. Maloni and J. A. Paul, "Evaluating capacity utilization options for US west coast container ports," Transportation Journal, vol. 52, no. 1, pp. 52-79, 2013.

[26] T. L. Yip, X. Y. Sun, and J. J. Liu, "Group and individual heterogeneity in a stochastic frontier model: container terminal operators," European Journal of Operational Research, vol. 213, no. 3, pp. 517-525, 2011

[27] M. M. González and L. Trujillo, "Efficiency measurement in the port industry: a survey of the empirical evidence," Journal of Transport Economics and Policy, vol. 43, no. 2, pp. 157-192, 2009.

[28] J.-F. Ding, "Applying fuzzy quality function deployment (QFD) to identify solutions of service delivery system for port of Kaohsiung," Quality \& Quantity, vol. 43, no. 4, pp. 553-570, 2009.

[29] M. R. Brooks, T. Schellinck, and A. A. Pallis, "A systematic approach for evaluating port effectiveness," Maritime Policy \& Management, vol. 38, no. 3, pp. 315-334, 2011.

[30] P. Simões and R. C. Marques, "Seaport performance analysis using robust non-parametric efficiency estimators," Transportation Planning and Technology, vol. 33, no. 5, pp. 435-451, 2010.

[31] S. Onut, U. R. Tuzkaya, and E. Torun, "Selecting container port via a fuzzy ANP-based approach: a case study in the Marmara Region, Turkey," Transport Policy, vol. 18, no. 1, pp. 182-193, 2011.

[32] J. Odeck and S. Bråthen, "A meta-analysis of DEA and SFA studies of the technical efficiency of seaports: a comparison of fixed and random-effects regression models," Transportation Research Part A: Policy and Practice, vol. 46, no. 10, pp. 15741585, 2012.

[33] P. Carvalho, R. C. Marques, Á. Fonseca, and P. Simões, “Governance and comparative performance of Iberian Peninsula seaports. An application of non-parametric techniques," International Journal of Transport Economics, vol. 37, no. 1, pp. 31-51, 2010. 
[34] A. S. Al-Eraqi, A. T. Khader, and A. Mustafa, "DEA Malmquist index measurement in Middle East and East African containers terminals," International Journal of Shipping and Transport Logistics, vol. 1, no. 3, pp. 249-259, 2009.

[35] H. S. Lee, M. T. Chou, and S. G. Kuo, "Evaluating port efficiency in Asia Pacific region with recursive data envelopment analysis," Journal of the Eastern Asia Society for Transportation Studies, vol. 6, pp. 544-559, 2005.

[36] Y. Wan, A. C.-L. Yuen, and A. Zhang, "Effects of hinterland accessibility on US container port efficiency," International Journal of Shipping and Transport Logistics, vol. 6, no. 4, pp. 422440, 2014

[37] J. L. Jiang, E. P. Chew, L. H. Lee, and Z. Sun, "DEA based on strongly efficient and inefficient frontiers and its application on port efficiency measurement," OR Spectrum, vol. 34, no. 4, pp. 943-969, 2012.

[38] N. Adler and B. Golany, "Including principal component weights to improve discrimination in data envelopment analysis," Journal of the Operational Research Society, vol. 53, no. 9, pp. 985-991, 2002.

[39] N. Adler and E. Yazhemsky, "Improving discrimination in data envelopment analysis: PCA-DEA or variable reduction," European Journal of Operational Research, vol. 202, no. 1, pp. 273-284, 2010.

[40] W. W. Cooper, L. M. Seiford, K. Tone, and J. Zhu, "Some models and measures for evaluating performances with DEA: past accomplishments and future prospects," Journal of Productivity Analysis, vol. 28, no. 3, pp. 151-163, 2007.

[41] A. Charnes and W. W. Cooper, "The non-archimedean CCR ratio for efficiency analysis: a rejoinder to Boyd and Färe," European Journal of Operational Research, vol. 15, no. 3, pp. 333334, 1984. 


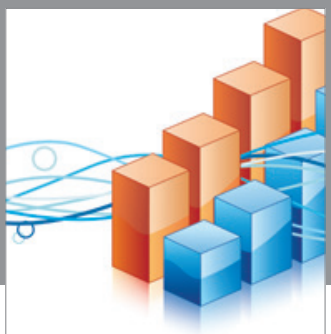

Advances in

Operations Research

vatem alat4

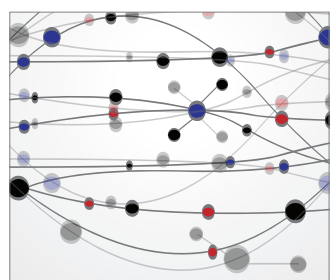

\section{The Scientific} World Journal
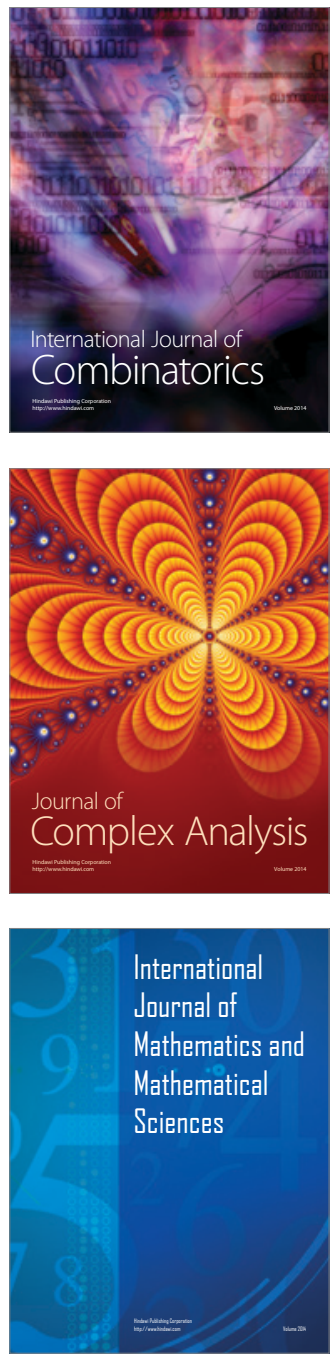
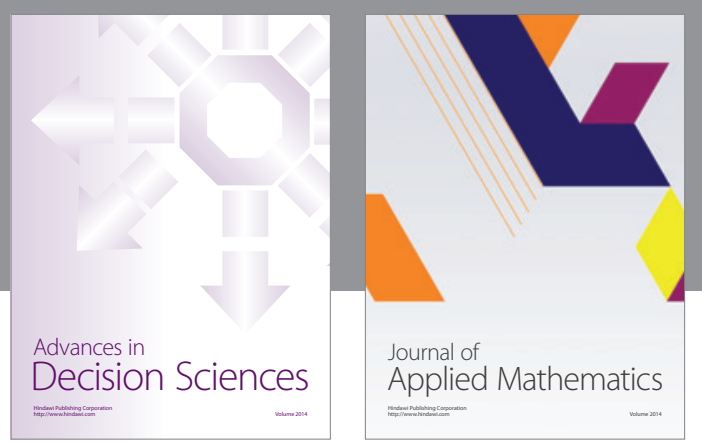

Algebra

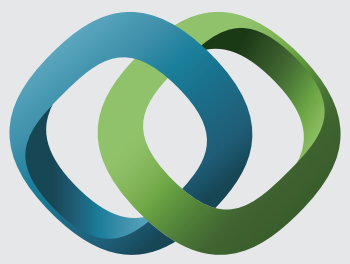

\section{Hindawi}

Submit your manuscripts at

http://www.hindawi.com
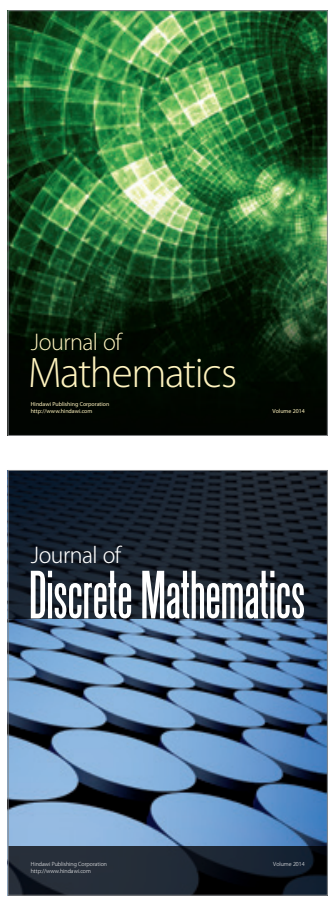

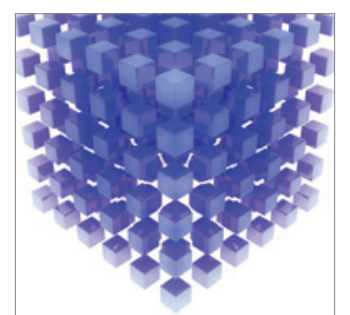

Mathematical Problems in Engineering
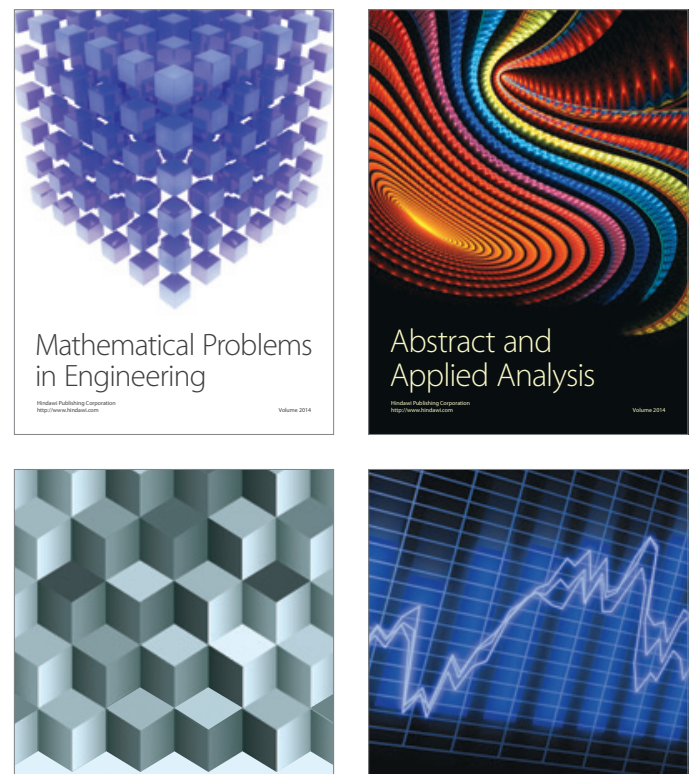

Journal of

Function Spaces

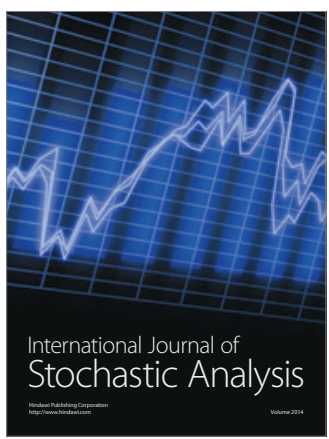

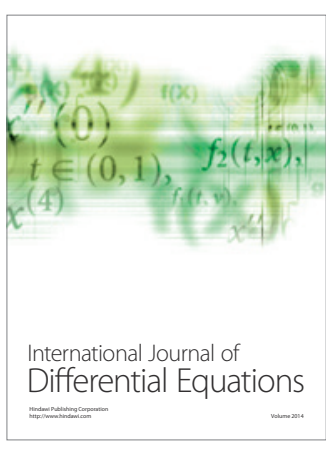
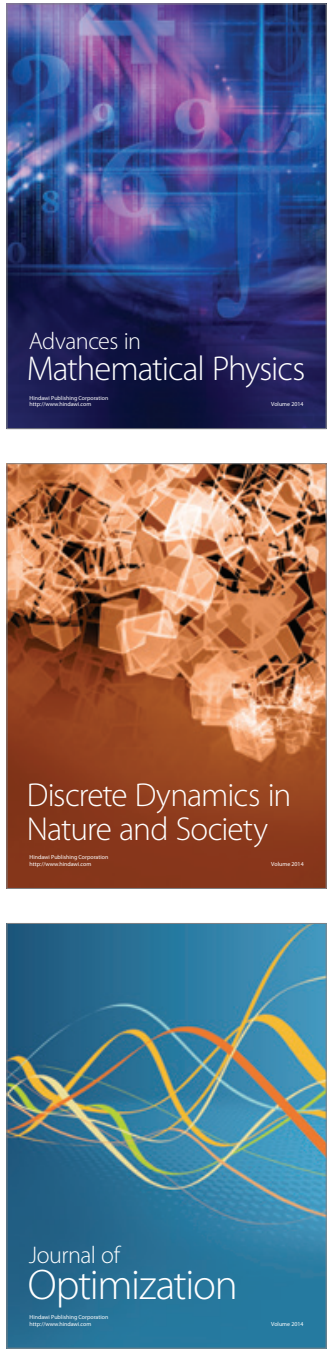